18

\title{
Luminescent Microthermometry of Laser Heating using Semiconductor Nanoplatelets*
}

(c) D. Gozhalskiy, T. Kormilina, V. Zakharov, S. Cherevkov, A. Dubavik, and A. Veniaminov

ITMO University,

197101 St. Petersburg, Russia

e-mail: gozhal.daniil@gmail.com

Received July 6, 2018

The effect of temperature on luminescence of semiconductor nanocrystals is used for monitoring local heating of specimens studied at laser scanning microscope. The spectral position of luminescence maximum is a convenient parameter to be followed; its thermal shift remains nearly linear within a broad temperature range. Nanoplatelets are found advantageous nanosized temperature sensors as compared to quantum dots due to narrower luminescence spectrum.

DOI: $10.21883 /$ OS.2018.11.46842.221-18

\footnotetext{
* International Conference „PCNSPA 2018 - Photonic Colloidal Nanostructures: Synthesis, Properties, and Applications“", Saint Petersburg, Russia, June 4-8, 2018.

Полный текст статьи опубликован в английской версии журнала.
} 